\title{
The Senior Internet User: Lessons From The Cybernun Study
}

Deborah J. Smith, (Deborah.Smith@esc.edu), Empire State College

\begin{abstract}
How do senior citizens view computers? What can help or hinder their use of today's digital technologies? "The Cybernun Study: Religious Sisters, Life Satisfaction and Computer Use" examined computer use and life satisfaction of senior religious sisters; also addressing computer usability concerns of senior citizens. A sample was obtained of 103 nuns in Upstate New York.; self-identified as computer users (CU) or non-users (NU). Nuns completed demographic information, two structured surveys and responded to additional semi-structured questions in selected interviews. Analysis of the open-ended responses found interesting differences in sister's perceptions of computer use.
\end{abstract}

\section{INTRODUCTION}

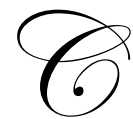

omputers and digital equipment are a part of modern life. The ability to use technology is quickly becoming an expected skill along with reading and computation skills in education. Much has been written on the changing expectations and experiences of children who are "growing up digital" [31]. On the other end of the spectrum, of interest are the perceptions and use of computers by older persons, who matured in an age before television or color photography. The older user today may be in a financially favorable position to invest in computer software and hardware, provided the use of computers meets their needs. Senior users often find mental stimulation through contact with online groups, particularly those seniors with physical disabilities limiting their mobility. The use of computers may contribute to good mental functioning in later years. Seniors may find the use of computers advantageous compared with previous forms of communications or document production as well as a satisfactory means of furthering their knowledge and education by formal or informal means.

Computer use in religious congregations is also of interest. For example, faced with expanding roles in ministry yet facing declining vocations in many faiths, religious organizations of every faith tradition increasingly see the Internet and computers as a means to reach congregants. The Internet is another way to evangelize and spread knowledge to the faithful and gather potential new members [3]. Less investigated are the personal technology experiences of clergy and religious.

This study examined the computer use and perceived life satisfaction of a selected group of senior citizens: religious sisters over the age of 60 and the senior sister's perceptions of computer use, measured by standardized survey instruments, as well as interviews of selected subjects with semi-structured questions to identify themes in their perceptions of the computer.

\section{LITERATURE REVIEW}

Available research falls into three areas: retirement, religious sisters and senior citizen's computer use - all of which may influence life satisfaction of religious sisters over age 60.

\section{Retirement}

Research on successful retirement finds it is a process differing by gender, socioeconomic level, perceived opportunity in retirement and health status [4, 21, 25]. Some studies found that retirement had few differences for 
women or men; better predictors of retirement satisfaction were income, health, marital status and education [28]. However, differences emerged when these groups were stratified by employment sectors and gender. This showed a general "male model" of retirement - continuous work with increasing pay and ultimately retirement - does not consider either the social context of work, discontinuous work histories, domestic household labor or the situation of the working poor, for whom retirement is often not an option .

Many retirement satisfaction issues tie directly into socioeconomic factors affecting the labor market. Good health, good post-retirement income, and the ability to make informed choices about the retirement process were more likely to influence a person's perceived satisfaction in retirement [14, 25, 26, 29].

\section{Religious Sisters}

Research with religious sisters (nuns) has centered on reasons for the decline in vocations $[8,23]$ or the examination of good versus poor mental and physical functioning for religious sisters. The latter results continue in the longitudinal Nun Study, an exploration of factors which stave off the onset of chronic debilitating mental disorders such as Alzheimer's disease [6]. Additional studies compared physical functions (e.g., blood pressure) with lay women, concluding that psychosocial and lifestyle factors in the convent often led to a significant increase in life with good function in older years for the nuns [32].

\section{Computer Use}

Research on senior citizen's computer use highlights training as a major need for this population. Access to communication and information-gathering applications at home, customizing the computer interface, resources and utilization of adult education principles to customize training for the older adult learner have been identified as critical success factors with this population [13, 15, 17]. Lack of training, fear of technology and economic factors were cited in one study as the most significant reasons for technology refusal [11].

Other studies suggest there is a high satisfaction with computers if the interface accommodates senior's ways of interacting. Yarnold and colleagues tested a questionnaire with seniors in both pencil-and-paper format and on the computer, With the computer touch screen, user satisfaction was high [34]. In another study, the use of a touch screen to assist Japanese elders in learning to send email was shown to greatly reduce the senior's anxiety about computer use [33].

Studies such as those conducted by Age Concern in the United Kingdom suggest common feelings in new senior computer users are uncertainty and fear, but as seniors gain in their computer abilities these feelings diminish. Women seniors used the computer to contact family and friends, or to research vacations and airline flights. Senior men used the Internet for research and information gathering more than women. Most users owned a home computer, although some of the subjects accessed the Internet from work (those aged 55-64) while a smaller number used family or friend's computers, Internet cafes and the public library [1].

The Pew Foundation's research on senior Internet use found only 22\% of American seniors online. Among those seniors using the Internet, sending email, doing product research, accessing medical information or visiting government websites were favored activities. Wired seniors, while equal in gender distribution, also tend to be white, better educated and from moderate-to-higher income levels. Like their British counterparts, US seniors use the Internet for travel reservations, as well as other purchases. Also noted in this report was a $136 \%$ increase in seniors using the Internet between 2000-2003 to obtain religious and spiritual information [12]. The opportunity for learning to undertake independent, fulfilling activities in later life has a greater impact on retirement satisfaction than the simple notion of age [27].

Drawing these three disparate areas together, the declines in membership in religious orders has left many orders concerned about the healthcare needs, both physical and mental, of a rapidly-aging congregation of sisters with dwindling numbers of newer members to care for them. This can directly impact both the longevity with good functioning of these nuns, as well as their perceptions of successful retirement in general. Computer use has the 
potential to assist senior religious sisters with needed knowledge, the ability to access information and communicate from their convent homes about issues of importance, allowing them some control over their retirement and their world.

Religious sisters who use computers often share a common collection of hardware and software, posing challenges in technology access. As adult learners, senior sisters may welcome the challenge of computer technology in order to enhance their ability to complete tasks, access information and communicate with others at a distance. A secondary effect may be increases in their sense of life satisfaction. Research suggests that senior sister's views on computer use and the potential impact of computer use on their life satisfaction may also point to issues which could improve and promote computing for the older person.

\section{PURPOSE AND METHODS}

This study attempted to answer two research questions:

1. Do senior religious sisters who use computers report greater life satisfaction as measured by the Life Satisfaction Index-Z (LSIZ) than those senior sisters who do not use computers?

2. What are senior religious sisters' perceptions of computer use as measured by the Attitudes Toward Computer Use Scale (ATCUS)?

Follow-up interviews with selected subjects were conducted to determine themes in the sister's view of computers and whether these themes differed by ACTUS score. Use of computers was considered the independent variable, while life satisfaction was considered the dependent variable in this descriptive exploratory study.

\section{Sample}

A convenience sample was obtained of 103 religious Sister volunteers over the age of 60 from seven different orders located in the Roman Catholic Diocese of Albany, New York. Each sister participant had been in the religious order for at least 40 years. Demographic and computer-use data were obtained on all participants and included years of computer use and the sister's age in years. Highest level of education, self-perception of health, and whether the nun regarded herself as "retired" or still working were obtained. Patterns of social contact were collected to see the major methods senior sisters used to keep in touch with family, colleagues and friends.

Among computer users, the largest group of users (55\%) had 1-5 years of experience, with $34 \%$ of the total computer users having 1-2 years of experience online. Participants in this study ranged in age from 60-95 years old and were both self-identified as computer users (CU) and non-users (NU).

\begin{tabular}{|c|c|}
\hline \multicolumn{2}{|c|}{ Table 1: Years of Nun's Computer Use } \\
\hline Years of Use & Percentage of Total Users $(\boldsymbol{N}=53)$ \\
\hline Less than 12 months & $17 \%$ \\
\hline $12 \mathrm{mo}-2 \mathrm{yr}$ & $34 \%$ \\
\hline $2.1-5 \mathrm{yr}$ & $21 \%$ \\
\hline $5.1-10 \mathrm{yr}$ & $8 \%$ \\
\hline $10.1-15 \mathrm{yr}$ & $8 \%$ \\
\hline$<15 \mathrm{yr}$ & $12 \%$ \\
\hline Total & $100 \%$ \\
\hline
\end{tabular}




\begin{tabular}{|c|c|c|c|}
\hline \multicolumn{5}{|c|}{ Table 2: Nun Sample Demographics: Age in Years (N=103) } \\
\hline Variable & Total & Nuns Using Computers (N=53) & Nuns Not Using Computers $(N=50)$ \\
\hline $60-64$ & $13 \%$ & $15 \%$ & $6 \%$ \\
\hline $65-69$ & $11 \%$ & $17 \%$ & $18 \%$ \\
\hline $70-74$ & $17 \%$ & $13 \%$ & $24 \%$ \\
\hline $75-79$ & $19 \%$ & $15 \%$ & $20 \%$ \\
\hline $80-84$ & $23 \%$ & $26 \%$ & $24 \%$ \\
\hline $85-90$ & $17 \%$ & $10 \%$ & $6 \%$ \\
\hline Over 90 & - & $3 \%$ & $100 \%$ \\
\hline Total & $100 \%$ & $99 \% *$ & \\
\hline
\end{tabular}

In this study, $63 \%$ of sisters indicated they were "retired" and the self-reported health of $80 \%$ of participants varied from "good" to "fair." While $64 \%$ of CU sisters were educated at the Master's level, $50 \%$ of NU sisters held Master's degrees, with the rest at the Bachelor or Associates degree level.

\begin{tabular}{|c|c|c|c|}
\hline \multicolumn{4}{|c|}{ Table 3: Nun Sample Demographics: Education, Health, Work Status } \\
\hline \multicolumn{4}{|c|}{ a. Education $(N=103)$} \\
\hline Variable & Total & Nuns Using Computers (CU) & Nuns Not Using Computers (NU) \\
\hline High School & $14 \%$ & $13 \%$ & $14 \%$ \\
\hline Associates & $4 \%$ & $6 \%$ & $2 \%$ \\
\hline Bachelors & $21 \%$ & $11 \%$ & $32 \%$ \\
\hline Masters & $57 \%$ & $64 \%$ & $50 \%$ \\
\hline Doctorate & $4 \%$ & $6 \%$ & $2 \%$ \\
\hline Total & $100 \%$ & $100 \%$ & $100 \%$ \\
\hline \multicolumn{4}{|c|}{ b. Health $(N=103)$} \\
\hline Variable & Total & Nuns Using Computers (CU) & Nuns Not Using Computers (NU) \\
\hline Excellent & $17 \%$ & $23 \%$ & $10 \%$ \\
\hline Good & $58 \%$ & $64 \%$ & $52 \%$ \\
\hline Fair & $22 \%$ & $9 \%$ & $36 \%$ \\
\hline Poor & $3 \%$ & $4 \%$ & $2 \%$ \\
\hline Total & $100 \%$ & $100 \%$ & $100 \%$ \\
\hline \multicolumn{4}{|c|}{ c. Work Status $(N=101)$} \\
\hline Variable & Total & Nuns Using Computers (CU) & Nuns Not Using Computers (NU) \\
\hline Working & $37 \%$ & $71 \%$ & $66 \%$ \\
\hline Retired & $63 \%$ & $29 \%$ & $34 \%$ \\
\hline Total & $100 \%$ & $100 \%$ & $100 \%$ \\
\hline
\end{tabular}

Most sisters (98\%) kept in touch with family and friends by non-digital means: letters, telephone calls and personal visits. But $20 \%$ of the total also used electronic mail as a means to communicate with family, friends or others in their order at a geographical distance.

\begin{tabular}{|c|c|c|c|}
\hline \multicolumn{3}{|c|}{ Table 4: Nun's Social Contact } \\
\hline Variable & Total & Nuns Using Computers (CU) & Nuns Not Using Computers (NU) \\
\hline Contact & $98 \%$ & $92 \%$ & $5 \%$ \\
\hline No Contact & $2 \%$ & $8 \%$ & $100 \%$ \\
\hline Total & $100 \%$ & $100 \%$ & Contact Methods \\
\hline \multicolumn{3}{|c|}{ Visit, write or phone $80 \%$} \\
\hline
\end{tabular}


The CU sisters utilized a wide variety of software and computer applications. Chief among these were electronic mail and word processing ( $83 \%$ and $81 \%$ of $\mathrm{CU}$ sisters, respectively) while searching the Internet for a specific topic or item, and playing computer games were popular with more than half the CU nuns. Combining the top applications, some orders of nuns also receive a monthly or weekly newsletter, from the central motherhouse, composed in word processing software and digitally delivered to the individual nun's email address.

\begin{tabular}{|c|c|}
\hline \multicolumn{2}{|c|}{ Table 5: Software And Online Applications Used By Percentage* (N=53) } \\
\hline Electronic mail & $83 \%$ \\
\hline Word processing & $81 \%$ \\
\hline Internet searches-specific & $62 \%$ \\
\hline Computer games & $54 \%$ \\
\hline Internet surfing & $44 \%$ \\
\hline Access website for one's order & $44 \%$ \\
\hline Databases & $35 \%$ \\
\hline Spreadsheet applications & $21 \%$ \\
\hline Paint or graphics software & $21 \%$ \\
\hline Downloads & $10 \%$ \\
\hline Other & $28 \%$ \\
\hline \multicolumn{2}{|l}{} \\
\hline
\end{tabular}

\section{Quantitative Instrumentation}

A standardized instrument, the Life Satisfaction Index-Z (LSIZ), is an 18-item instrument designed to measure psychological wellbeing and life satisfaction in the elderly. Specifically designed for oral or written use with persons over the age of 65, the LSIZ was developed from the parent tool--the Life Satisfaction Rating Scale (LSRS). The LSIZ shows moderate correlations with the LSRS, indicating some concurrent validity. Items on the scale were selected from correlations with the LSRS and their ability to discriminate between high and low scorers on the LSRS scale, also indicating known-group validity for the LISZ. Original rating scales from which the LSIZ came had excellent inter-observer agreement [22].

Reliability data for the LISZ ranges from an alpha of .70 in Dobson's research [7] to .90 obtained in a study done by Edwards and Klemack [9]. Regarding validity, in a study which compared the LSIZ to other life satisfaction instruments, correlations ranged from .94 with the Life Satisfaction Index-A (the original version of the scale) and .79 with the Philadelphia Geriatric Center Morale Scale [20].

The LSIZ is scored by assigning one point to each correct item and summing the scores. "Agree" is the correct response on certain items, while "disagree" would be the correct response for others. Therefore the final score indicates a total for satisfaction with one's life in ascending order. The highest score that may be obtained is 18, with a range of 0-18 possible.

An instrument for measuring computer use is the Attitudes Toward Computer Usage Scale (ACTUS). The ACTUS is a 20 -item scale developed using college undergraduates and carries an internal consistency estimate of .84 and test-retest correlation of .91 [24]. Subsequent studies with samples of older adults found the ACTUS factor structure to be similar [2]. In examining convergent validity for a number of computer attitude scales, researchers found that the ACTUS indicated significant relationships between the scale and hours of computer use, number of college computer courses and self-reported computer anxiety. The revised ACTUS is a twenty-item scale (reduced from forty items) with an alpha coefficient of .84 [36]. Each question on the Likert-type scale is assigned a weight from 1 to 7. Depending on whether the question is negatively weighted (7 to 1$)$ or positively weighted (1 to 7 ) the chosen responses are added to produce a total score from 20 to 140. Low scores are indicative of positive perceptions of computers and technology, while high scores indicate negative perceptions of the same. The final question of the ATCUS rates self-perceived computer anxiety on a simple 1 to 5 rating, with one as "least" and 5 as "most" anxious. 


\section{Data Analysis}

Percentages were used to compile descriptive statistics of self-reported computer users (CU) and non-users (NU). Differences in LSIZ scale scores were analyzed by means of a t-test, while scores from both the ACTUS and the t-test were run in a correlation matrix against demographic variables. Data was also run in an ANOVA and a logistic regression to determine significance at the .05 level. All results were reported as aggregate data.

\section{QUALITATIVE DATA COLLECTION}

\section{Sample}

Several sisters were selected for follow-up interviews: the 6 highest ACTUS scorers (negative perception of computers) and 6 lowest ACTUS scorers (positive perception of computers) and 5 of the highest scorers on the LSIZ scale (greatest life satisfaction) were interviewed with predetermined questions regarding their perceptions of technology.

So tell me about you and computers...or not...

\section{Table 6: Interview Questions}

What are the advantages and disadvantages that you see to computers?

The survey talked about using computers in educational settings: what do you see as the advantages and disadvantages of technology in the schools?

For you, in a nutshell, what is the point of technology?

The last survey question stated: "I feel that technology has helped to improve our lives." How do you feel about that statement now? (Remember that technology in the survey is more than just a computer...)

Have computers increased your satisfaction with your life? Why or why not?

During the interview, CU sisters would often describe in detail problems they encountered with learning a computer or maintaining competency in computing. Occasionally, they would sit at the computer and show the interviewer what they were talking about, and how this problem impacted their daily computer use. These issues were noted by the interviewer, in addition to other reviewers who pinpointed common themes across the written notes/taped conversations of all interviewed sisters. (For those few sisters who refused to be taped, written notes were taken on the interview.)

Many older sisters are involved with projects different from those they once held in prior ministry, which actively support the work and communal calling (charism) of their orders. Perhaps the computer, with its ability to link others together instantly over time and space, to produce near-perfect documents and allow easy manipulation of data, graphics or information could enhance life satisfaction for a retired nun. While the quantitative data did not support this analysis, the themes which emerged from the interviews with the sisters showed some elements of computer use that were beneficial. There were also areas of concern about computer use which could inform future efforts to attract and keep senior computer users.

\section{RESULTS}

\section{Quantitative Data}

In regard to the first research question: "Do senior religious sisters who use computers report greater life satisfaction as measured by the (LSIZ) than those senior sisters who do not use computers?" no statistical significance was found. Life satisfaction is a construct with many dimensions: the use of technology tools does not weigh heavily enough to influence other contributing factors. 
The second research question: "What are senior religious sister's perceptions of computer use as measured by the Attitudes Toward Computer Use Scale?" showed CU sisters and NU sisters held differing views between the highest and lowest scorers on the scale.

\section{Qualitative Data}

In looking at the qualitative results, several themes emerged from the data. The individual categories are discussed for CU sisters first, then for NU sisters.

Computer-Using Sisters

There were four general themes identified by the interviews with the sisters selected in this study. These themes reflected the nun's perceptions of the computer as a device with many abilities, but one which often posed challenges.

a. Communication

$\mathrm{CU}$ sisters saw technology as a tool, not a realm for virtual worlds or online relationships in real time or asychronously (i.e., discussion databases.) The most used application was electronic mail. Email was an established means of communication for $20 \%$ of the CU study participants, who used this for purposes of their ministry, socialization with family and contact with friends. While on the Internet, most CU sisters favored visiting websites for their religious order or the Vatican, news services like Zanet or CNN, sending e-greeting cards and online shopping.

\section{b. $\quad$ Mastery}

Many CU sisters began their use for employment reasons, or as part of their ministry. CU Sisters, half of whom were still employed at the time of this study, often began computer use at work as stated earlier, but a smaller group of CU nuns became intrigued when they visibly saw what a computer could do. Viewed as a challenge rather than a hindrance, the technology anxiety of CU nuns decreased with time and practice. CU sisters often spoke about the excitement they found in learning to use a computer.

\section{c. Internet Safety}

The Internet itself was viewed as a repository of global information, which allowed a nun to quickly access current news, archived documents or connect with others in their order worldwide at the click of a mouse. While concerned about dangers on the Internet, $\mathrm{CU}$ sisters did not see this as a reason for them to curtail computer use, but rather as another compelling reason to practice online safety measures.

\section{d. Benefits}

The CU sister frequently reported she could do better work in a more timely fashion. For instance, CU sisters could continue uninterrupted with the duties of their personal ministries by ordering supplies and equipment needed online, tracking their expenditures and keeping large amounts of data in databases and spreadsheets, etc. Computer use made task accomplishment easy, clear and visually acceptable; it allowed the CU nun to complete a project in a timely fashion, then move on to other tasks. The nuns often described these immediate personal benefits computing brought to them.

\section{e. Other issues}

Often, CU sisters encountered interface problems. Small type, difficulty with pages loading, slowing of the Web during high-demand times on dial-up connections and the proliferation of confusing advertisements and poor signage on websites were cited as issues. Most sisters worked with shared equipment rather than single-user home computers, which posed a variety of challenges in regard to adjustment of the interface, storage of data and 
maintaining the computer workspace. For one order, the entire community of retired sisters shared three computers. CU sisters reported they individually discovered/determined a variety of ways to access and store information within a computer. This often created confusion if a particular view or display was selected by one person, but not desired by the others. Community hardware and software also creates the issue of who will maintain and organize these things [18].

Sisters with low vision or arthritis found the typical screen, a standard mouse or common desk chair difficult to use for extended lengths of time and were unaware of the availability of adapted peripherals for use.

\section{Non-Computer Using Sisters}

a. Communication

NU sisters saw technology as a tool too, but one that they perceived as much more difficult to master. Many NU sisters expressed either a lack of interest, or preference for personal face-to-face or voice-to-voice contact instead of learning to use a computer. The NU sisters preferred the use of postal mail for communications; or television, newspapers and radio for information gathering, rather than using email or searching the Internet.

b. Mastery

For NU sisters there were several reasons identified for technology refusal. Many felt it was too taxing or a tool for younger people; some disliked the instruction methods, or experienced difficulty with the interface or peripherals, while some sisters believed it isolated people from one another [11].

NU sisters stated they were "not interested" in the computer, in contrast to CU sisters in the initial stages of learning to navigate the Internet. CU sisters often could not recall what steps to follow in order to access a URL or return to a page, but persisted to master the task. This pointed to the role of memory in learning computer use; as well as the difference between the passive viewing of a television screen versus the active clicking to obtain information needed on a website.

c. Internet Safety

NU sisters often cited the dangers of the Internet, which parallel those portrayed in the mass media, as a reason not to use a computer (e.g., child luring, hacking and identity theft, online stalking.) These dangers were of concern to both $\mathrm{CU}$ and $\mathrm{NU}$ nuns since the education of children had been a part of their ministry for a majority of the sisters.

d. Benefits

NU sisters could appreciate the global impact of technology, often describing how future developments would benefit society as a whole. While they did not identify computer use as something of personal benefit, NU sisters felt that computers may eventually impact their lives in the areas of medicine and research.

\section{DISCUSSION}

This study was conducted with a volunteer population of religious sisters, residing in Upstate New York. As such the communal, single religious lifestyle as well as access to shared computer hardware and software, limits complete generalization of the findings. The results of interviews with both CU and NU sisters, however, do suggest some pertinent usability issues in computer access for the senior citizen population.

\section{Communication}

For the senior CU sister, the computer is a communications tool which allows her to quickly correspond by email across the globe. Many sisters described reconnecting with others in their order by email, which had the dual 
advantage of eliminating costly phone bills or watching the clock to calculate time zone changes. Email was quick; once the recipient replied to the sister's message, it took only moments for the message to arrive, not weeks as would happen in a postal letter. In contrast, NU sisters often described a preference for a "personal touch" which translated into a handwritten letter or a voice over a phone line.

\section{Mastery}

The challenge of recall also impacts both $\mathrm{CU}$ and NU sisters, often leading the latter to prefer forms of communication with which they are already familiar. In one training program, sisters were often seen staring at the computer monitor waiting for a response, much like waiting for the television commercials to end and the program to begin. The sister would eventually ask: "What do I do now?" but had difficulty generalizing from the passive watching of television to the active clicking required in a hypertext world [30]. While this was true even of CU sisters in the beginning stages of learning, the CU nuns described an excitement in learning to master the computer and accomplishing tasks with the machine, that far outweighed what they could do by hand--which increased their satisfaction and ease with computer use.

\section{Internet Safety}

While all of the nuns interviewed agreed that there are dangers on the Internet, CU nuns took this opportunity to practice online safety procedures rather than curtail computing. NU sisters cited dangers that they often heard about or saw via the mass media, which became another reason not to engage the computer.

\section{Benefit}

The perception of benefits derived from computing was clearly different between CU and NU sisters. CU sisters described using a computer for current information, online product ordering, account tracking, production of timely and better-looking work, as well as the reach and speed of email. They could detail the personal direct benefits obtained from computing. Since this study, one participating order has now installed computers in the convent retirement home and taught their senior sisters how to order and refill their medications online. Many international orders, in offering rooms for visitors and pilgrims, accept reservations via email.

NU sisters, in contrast, described the impact of technology in research and the global reach of information; they could also imagine how advances in areas such as computer-aided medicine and research might benefit them in future. NU responses tended to see computer use from a global, indirect perspective.

\section{ISSUES FOR SENIOR COMPUTER USERS}

The lessons of the Cybernun study fall into the categories of accommodations for technology and usability issues [16]. These rules-of-thumb are derived from observation during work with nuns using computers, comments or demonstrations made during the interviews in the present study, or from the literature $[11,15,17,30]$.

During the interview stage of this study, the sisters would frequently describe a variety of concerns. The impact of health and memory, and the degree to which it limits the user's ability to comfortably access information and do work at a computer, can directly contribute to continued use, perceptions of ease of use, and interest in computing. The principles of adult education, clearly described by Czaja and Lee, are useful in work with this population-whether the senior sees a computer as a hobby or as a task tool [5].

The easier it becomes for a sister to use a computer function, the more likely her technology skills will increase, along with the perceived benefits of computer use. Increasing skill levels help a senior user recognize and avoid cyberspace dangers, and diminish their concerns about further mastery of hardware and software $[5,10,33,35]$. 


\section{Peripherals}

For the user with disabilities or with an aging population, physical comfort is often a key issue in computer use. A wireless and ergonomically correct mouse and keyboards can help minimize the effects of chronic conditions like arthritis. Support for wrists and arms, as well as ergonomically correct seating, in locations free of screen glare, support successful computer use by individuals. Peripherals such as large-screen monitors should be offered free or at a reduced charge at the time of purchase or during upgrades to computer equipment for a senior citizen. Community service agencies, like the Association for the Blind in the United States are often willing to provide assistance in this regard.

\section{Computer Location}

Not only the computer interface, but the placement of items like the hard drive, scanners, speakers and printers should be in areas where excessive bending and twisting of the body can be avoided if these will be handled by older or disabled users. This is also important for a designated person who monitors the computer area, but more so if several people with various levels of physical limitation have access to these items.

\section{Text Size}

Large type manuals should be an option for the user at the time of purchase. Large screen monitors to increase the size of print are valuable for those with low vision, as are instructions regarding how to increase font size on the monitor. Instructions of any sort should always be in large print with fonts no lower than 12 points. Instructions involving manipulation of the computer display should be prominently posted in large type near each computer in areas of shared equipment, as well as "reverse instructions" if the original settings need to be restored when a user's session on the computer has ended.

\section{Web Visual Interfaces}

Additionally, development of websites for seniors should take into consideration ease of use for this population. White backgrounds for web pages are best; avoiding dark colors or designs in the background. Highlighting critical information makes viewing the content of a web page easier for the older eye, as does the use of fonts and colors in other than the blue-green range [15]. Website design aimed at the senior population should consider the average age and abilities of the potential users, working with senior's longer response times. Easily accessed information should be presented in consistent locations on the page, without irrelevant information or dense areas of text. Feedback from usability trials of such websites can give invaluable clues about how older users navigate information and interpret cues within the content area itself while working within the physical limitations of advancing age $[15,19]$.

For example, the website of the Community of the Sacred Heart (www.rscj.org) contains a passwordprotected area for nuns in this order. Individual sisters receive the password to the site, which is not available for general distribution. It is in this private area, for example, taking into account the advanced age of most sisters that accommodations such as large type could be beneficial. The website itself, while featuring teal blue as a secondary color on the page, uses white in major text areas, surrounded by a mauve and red-purple color scheme.

\section{Adult Learning Principles}

Adults learn best when previous interests and experience are tied to new learning, building on prior knowledge and going from simple to complex. Time should be allotted for hands-on practice, clarification and questions with increased time allotted for older user's task response. Advance organizers, as well as explaining curriculum progression, helps the learner understand what will be covered in class. Keeping the class size small facilitates mastery for the user. Safety advice integrated within the curriculum, rather than detailed entirely in one lesson, and nowhere else allows the learner to practice safety in everyday computer use $[1,5,12,16]$. 


\section{CONCLUSION}

Recommendations for increasing senior citizen's computer use also address the issues encountered by the Cybernun Study. Bearing in mind the health problems frequently encountered in older people, ergonomic computer accommodations and large print are advocated to increase the comfort of the user in text-heavy Internet environments. Considering the location of computer labs and individual computers can decrease common user frustrations. The principles of adult education, including hands-on experiences which decrease technology anxiety and advance organizers to guide learning, are of great value. Clear directions on how to alter the standard interface (and return it to default for multiple users) can help with shared equipment, as do usability trials of Internet-based information aimed at seniors, providing feedback on ease of use and usefulness of the information available.

\section{REFERENCES}

1. Age Concern (2002) The internet and older people. http://www.ageconcern.org.uk/AgeConcern/media /Quant_exec_report_ext.pdf. Cited 2002

2. Brown, TS, Brown, JT, and Baack, SA (1990) Attitudes of the elderly towards computers. The Journal of Computer Information Systems 31: 28-33

3. Budde, ML, (1998) Embracing pop culture: The Catholic church in the world market. World Policy Journal 77-87

4. Calasanti TM (1996) Gender and life satisfaction in retirement: An assessment of the male model. Journal of Gerontology: Social Sciences 518(1): S18-S29

5. Czaja SJ and Lee, CC (2003) Designing computer systems for older adults. In: Jacko JA and Sears A (eds) The Human-Computer Interaction Handbook, Lawrence Erlbaum Associates, Mahwah, N.J 413-427

6. Danner D, Snowdon D, and Friesen W (2001) Positive emotions in early life and longevity: Findings from the nun study. Journal of Personality and Social Psychology 80(5): 814-813

7. Dobson C, Powers EA, Keith, PM, and Goudy WJ (1997)Anomie, self-esteem and life satisfaction: Interrelationships among three scales of well-being. Journal of Gerontology 34 (4): 569-572

8. Ebaugh HR, Lorence J, and Chafetz JS (1996) The growth and decline of the population of catholic nuns cross-nationally, 1960-1990: A case study of secularization as social structural change. Journal for the Scientific Study of Religion 35(2): 171-183

9. Edwards, JN and Klemmack DL (1973) Correlates of life satisfaction: A re-examination. Journal of Gerontology 28: 479-502

10. Eisma R, Dickinson A, Goodman J, Syme A, Tiwari, L, and Newell AF (2004) Early user involvement in the development of information technology-related products for older people. Universal Access in the Information Society 3(2): 131-140. DOI: 10.1007/s10209-004-0092-z Cited 2004

11. Festervand TB, Meinert DB, and Vitell SJ (1994) Older adult's attitudes toward the adoption of personal computers and computer-based lifestyle assistance. Journal of Applied Business Research 10(2):13-22

12. Fox S (2004) Older Americans and the internet. Washington DC: Pew Internet \& American Life Project http://www.pewinternet.org/pdfs/PIP_Seniors_Online_2004.pdf. Cited 2004

13. Galusha JM (1998) The use of computer technology by older adults: CE 075850. ERIC Document Reproduction Service no. ED416380

14. Hardy MA and Quadrango, J (1995) Satisfaction with early retirement: Making choices in the auto industry. Journal of Gerontology: Social Sciences 50B(4): S217-S228

15. Hawthorne D (2000) Possible implications of aging for interface designers. Interacting with Computers 12(5): 507-528

16. Hendrix CC (2000) Computer use among elderly people. Computers in Nursing 18(2):62-68

17. Irizarry C, Downing A, and Elford C (1997) Seniors online: Introducing older people to technology. Australasian Physical \& Engineering Sciences in Medicine 20(1):39-43

18. Lally E (2002) At home with computers. Berg, New York

19. Meghreblian K (2004) Search engine optimization and web site usability. Webpronews.com http://www.webpronews.com/ebusiness/seo/wpn-4-20040311SearchEngineOptimizationand WebSiteUsability.html. Accessed 2004 
20. McDowell I and Newell C (1987) The life satisfaction index. Measuring health: A guide to rating scales and questionnaires. Oxford University Press, New York

21. Moen P (1996) A life course perspective on retirement, gender and well being. Journal of Occupational Health Psychology 1(2): 131-144

22. Neugarten BL, Havinghurst RJ, and Tobin SS (1961) The measurement of life satisfaction. Journal of Gerontology 16: 134-143

23. Nygren DJ and Ukeritis MD (1993) The future of religious orders in the United States: Transformation and commitment. Praeger, Westport, CT

24. Popovich PM, Hyde KR, Zakrajsek T, and Blumer, C (1987) The development of the attitude toward computer usage scale. Educational and Psychological Measurement 47: 261-269

25. Quick HE and Moen P (1998) Gender, employment and retirement quality: A life course approach to differential experiences of men and women. Journal of Occupational Health Psychology 3(1), 44-64

26. Rosenkotter MM and Garris JM (1998) Psychosocial changes following retirement. Journal of Advanced Nursing 27(5): 966-976

27. Ross CE and Drentea $\mathrm{P}$ (1998) Consequences of retirement activities for distress and the sense of personal control. Journal of Health \& Social Behavior 39(4): 317-334

28. Seccombe, K and Lee, GR (1986) Gender differences in retirement satisfaction and its antecedents Research On Aging 8(3): 426-440

29. Slevin K and Wingrove CR (1995) Women in retirement: A review and critique of empirical research since 976. Sociological Inquiry 65(1): 1-21

30. Smith, DJ (2001) The cybernuns: Religious sister's perceptions of computer training. Journal of Ministry Marketing \& Management. 6(2): 19-30

31. Tapscott, D (1999) Growing up digital: The rise of the net generation. McGraw-Hill, New York

32. Timeo M, Saronio P, Venanzi S, Gentili S, Vendura C, and Timio F (1999) Blood pressure in nuns in a secluded order: A 30-year follow-up. Mineral and Electrolyte Metabolism 25(1/2): 73-79

33. Umemuro H (2004) Lowering elderly Japanese user's resistance towards computers by using touchscreen technology. Universal Access in the Information Society 2(2): 305 DOI: 10.1007/s10209-004-0098-6. Cited 2004

34. Yarnold PR, Stewart MJ, Stille FC, and Martin GJ (1996) Assessing functional status of elderly patients via microcomputer. Perceptual \& Motor Skills 82(2): 689-690

35. Zajicek M, Wales R, and Lee A (2004) Speech interaction for older adults. Universal Access in the Information Society 3(2) 122-130 DOI 10.1007/s1 0209-004-0091-0. Cited 2004

36. Zakrajesek TD, Waters LK, Popovich PM, Craft, S, and Hampton WT (1990) Convergent validity of scales measuring computer-related attitudes. Educational and Psychological Measurement 50: 343-349.

This article is dedicated to the memory of Sr. Marguerite Cleary, RSCJ; the original Cybernun. 